\title{
How professional sports clubs exploit a heterogeneous local potential: the case of Swiss professional ice hockey
}

\section{Emmanuel Bayle, Markus Lang \& Orlan Moret}

To cite this article: Emmanuel Bayle, Markus Lang \& Orlan Moret (2019): How professional sports clubs exploit a heterogeneous local potential: the case of Swiss professional ice hockey, Sport in Society

To link to this article: https://doi.org/10.1080/17430437.2020.1696524

曲 Published online: 04 Dec 2019.

Submit your article to this journal $\pi$

Q View related articles $\llbracket$

View Crossmark data ¿ 


\title{
How professional sports clubs exploit a heterogeneous local potential: the case of Swiss professional ice hockey
}

\author{
Emmanuel Bayle, Markus Lang and Orlan Moret \\ Institute of Sport Sciences, University of Lausanne, Lausanne, Switzerland
}

\begin{abstract}
Switzerland's National League is the world's third most high-paying ice hockey championship after the $\mathrm{NHL}$ and the $\mathrm{KHL}$, even though Switzerland is a small country with a population of 8.5 million and the league's professional clubs are based in areas that vary enormously in terms of their local potential (demographic and economic). How do these clubs exploit such different local potentials? In this paper, we examine the relationship between a club's local potential and its commercial, financial and sporting results. Based on our data, we outline the specific characteristics of the different models adopted by Switzerland's first division ice hockey clubs and draw up an empirical typology of four types of club. Our study's contribution is both methodological and empirical. We describe an operational model that can be used to characterize local potential and three types of club expertise: marketing, managerial and sporting expertise.
\end{abstract}

\section{KEYWORDS}

Professional sports; location; regulation; ice hockey; Switzerland

\section{Introduction}

\section{History and background}

Ice hockey was first introduced into Switzerland at the end of the $19^{\text {th }}$ century via tourism and the country's boarding schools. As a result, it was at first mostly played by foreigners and was not taken up by the Swiss themselves until the end of World War I (Busset 2000). Ice hockey's subsequent growth was linked to the success of winter sports in Switzerland and by 1927 was one of the five obligatory sports for school students, alongside gymnastics, skiing, swimming and hiking. This brief social history explains why ice hockey is more popular and has attained a greater degree of professionalization in Switzerland than in neighboring countries. In addition, it appears to be used to affirm a distinctive national identity that sets Switzerland apart from other countries. Although the economic dimension may partly explain the current under-representation of people from immigrant backgrounds in Swiss ice hockey - most people who play ice hockey come from wealthier social groups, although there are also many working class players (Moret and Ohl 2019) - the cultural dimension must not be overlooked in so far as, in contrast with soccer, ice hockey is not a

CONTACT Emmanuel Bayle emmanuel.bayle@unil.ch Institute of Sport Sciences, University of Lausanne, Lausanne 1015, Switzerland 
major sport, or is not played at all, in the countries of origin of Switzerland's largest immigrant communities. This situation is reinforced by the regulations covering elite-level players. In contrast with soccer, the Swiss Ice Hockey Federation (SIHF), the governing body of ice hockey in Switzerland, has limited the number of foreign players since 1933 based on a gentleman's agreement between the clubs. ${ }^{1}$

However, Switzerland is by no means an 'ice hockey country' in the way the term applies to Canada, Finland and Sweden, where ice hockey plays an important symbolic role (Whitson and Grunenau 2006, Robidoux and Trudel 2006, Kidd 2013, Carlsson and Backman 2015). In addition, Swiss ice hockey is a niche sport with only 25,000 registered players. Nevertheless, it is a very popular spectator sport whose widespread media attracts a great deal of interest from the public (Lamprecht, Fischer and Stamm 2014). It is also Switzerland's second sport (behind soccer) in terms of sponsorship.

For several years, Switzerland's National League $(\mathrm{SNL})^{2}$ has been the world's second most popular ice-hockey league after the $\mathrm{NHL}^{3}$ and ahead of the KHL, ${ }^{4}$ with each match attracting an average of around 7,000 spectators (an occupancy rate of $87.5 \%$ for the 8,000 places available). This average of 7,000 spectators, achieved largely thanks to SC Bern, whose home games attract around 16,000 spectators, is much lower than the average attendance at NHL games (around 17,500 spectators) but impressively high for a country with only 8.5 million inhabitants.

The media's and spectators' enthusiasm for ice hockey in Switzerland (Moret et al. 2019), combined with the country's healthy economy, allows the SNL to be the world's third most high-paying ice hockey league, behind the NHL and KHL. Although players' salaries in Switzerland are much lower than those paid in the KHL and far behind those on offer in the NHL, they are much higher than the salaries paid in Sweden, Europe's second most prominent league. In 2019, the highest paid player in the NHL earned \$12.5 million (salary cap of $\$ 81.5$ million per team for the $2019 / 20$ season). In the KHL, this figure was $\$ 5.5$ million (salary cap of $\$ 15$ million per team, but this was not respected by some teams, which were sanctioned, and $30 \mathrm{KHL}$ players earned more than $\$ 1$ million). This figure was $\$ 800,000$ in Switzerland (no salary cap; only ten players earned more than $\$ 500,000$ ) and $\$ 250,000$ in Sweden. Unlike Europe's other top leagues (Sweden, Finland, Czech Republic), a large percentage of Swiss hockey players play in their home country, which substantially increases the clubs' wage bills.

In terms of sporting performance, Switzerland's national side is ranked $8^{\text {th }}$ in the world (and, most notably, won silver medals in the 2013 and 2018 world championships) and the SNL is recognized as one of Europe's top leagues (even if Swiss clubs have not performed particularly well in European competitions). Consequently, it is not surprising that many NHL stars chose to play in Switzerland during the 1994/95, 2004/05 and 2012/13 NHL lock-outs.

\section{Research question, aim and contribution of the paper}

The SNL has a peculiarity because the clubs participating in its championship are based in areas that vary enormously in terms of their local potential (demographic and economic). For example, clubs from very small villages such as Ambri (population 500) compete successfully against clubs from large metropolitan areas such as Zurich (population 1.3 million). Even though for the last five seasons, Zurich has tended to come out on top in its encounters 
with Ambri, the tiny club from the Tessin canton has won one in four games against the giant from Zurich (5 wins for Ambri, 15 wins for Zurich), and many of Zurich's wins were hard fought. In other words, despite having widely different local potentials, the glorious uncertainty of sport (Yonnet 1998) continues to be a feature of Swiss ice hockey. How can such differences continue to exist in a league that is so attractive and successful? Put differently, how do clubs with such limited local potentials continue to remain competitive?

The present paper attempts to answer these research questions by examining the relationship between a club's local potential and the commercial, financial and sporting performances the club manages to achieve. Based on our data, we outline the specific characteristics of the different models adopted by Switzerland's first division ice hockey clubs and draw up an empirical typology of four types of club: regional flagships, sporting high achievers with unexploited local potential, popular but modest clubs overshadowed by a larger rival and atypically successful clubs.

Our study's contribution is both methodological and empirical. From a methodological point of view, we describe an operational model that includes indicators for characterizing and measuring a club's local potential. We also describe indicators that can be used to measure three types of expertise: marketing, managerial and sporting expertise. This base can be used and improved so it can be tested in other countries and other sports. From an empirical point of view, our study is the first of its kind to examine ice hockey in Switzerland.

The remainder of the paper is organized as follows: Section 2 reviews the related literature. Section 3 introduces the underlying model. Section 4 explains the data and the methodology. In Section 5, we present and discuss the results. Section 6 concludes with a discussion and outlook for the future.

\section{Literature review}

\section{Local potential and revenue sources}

In Switzerland and Europe, the localization choice of clubs is not based on economic criteria but rather a result from historic and cultural aspects as well as sporting results through promotion and relegation in open leagues. Thus, the local potentials of the clubs can be very heterogeneous. In the closed North American major leagues, scholars have shown that franchises (clubs) try to establish themselves in densely populated and economically wealthy geographic regions (Augustin 1995, Bale 1993, Danielson 2001, Durand and Bayle 2002) to which we refer to as regions with high local (economic) potential. The literature in sports economics assumes that a club with a high local (economic) potential has a higher revenue potential than a club operating in a region with a low local potential (Quirk and Fort 1992, Szymanski 2003). ${ }^{5}$

A professional club has potentially four main types of clients: direct supporters, corporate clients, local government and the media. Historically, direct supporters have been the major financial resource (Fort and Quirk 1995). However, the ratio of revenues from this source has greatly declined in Switzerland since the 90's under the pressure of broadcasting and corporate clients (Andreff 2000, Andreff and Staudohar 2000). Although their financial contribution has been reduced, direct supporters nevertheless remain the cornerstone of a professional club. Moreover, merchandising and licensing rights are still a powerful opportunity for big clubs to exploit their 'brand'. 
Beyond quantitative factors, the quality of direct, local supporters is a key factor in location. These supporters can be characterized by complementary variables: their disposable income and likelihood to support the team, and their propensity to consume. Throughout the world, sports producers have chosen to "select" their direct supporters by raising ticket prices, thereby consigning the masses to watching the match on television (Fort and Quirk 1995, Szymanski 2003).

Small businesses and corporations constitute the second type of client (Copeland, Frisby, and McCarville 1996). Communication within and by means of sports has become a traditional method of promoting one's business. Business sponsors purchase advertising space in the vicinity of, and on, the playing field. These companies also commit to the purchase of public relations operations. For example, the creation of associated services (car park, restaurants, catering) also increases revenues. Although some clubs attract national or international brands as sponsors, the local presence of powerful companies is still a key element of success. These clients are relatively inelastic to prices and are generally solvent, offering a good market on a regional scale and even in some cases on a national scale.

The third type of client, local authorities, are found all over the world. Their financial assistance and their involvement vary markedly from one country to another, from one sport to another, and according to the level at which the club competes (Durand and Bayle 2002). In the North American major leagues, a powerful local government is a major condition for the location choice. It ensures that the club will benefit in several key areas: the construction and maintenance of facilities (arenas, skating rinks, etc.), as well as direct and indirect financial help (tax exemptions, purchases of services, and so on).

The media (in particular, television broadcasters) are the fourth source of financing for professional clubs (Quirk and Fort 1992). The major broadcasting companies have become the principal clients of many clubs and even, in many cases, of the leagues. This has been achieved by means of collectively negotiated contracts (Falconieri, Palomino, and Sákovics 2004). However, only a very few clubs and major leagues attract these clients, and the less prestigious clubs and the lower level championships benefit only through a system of solidarity. Thus, in principle, television rights may help to equalize the opportunities to attract national sports clubs, since location becomes less dependent on local potential.

\section{Regulation in professional team sports}

In contrast to Switzerland, all North American major leagues are heavily regulated (Dietl, Fort, and Lang 2011). Competitive imbalance, resulting in uninteresting games and skyrocketing player salaries, play a dominant role in the list of dangers cited in all attempts to regulate the major leagues (Rottenberg 1956, Neale 1964). Throughout their history, the major leagues have employed a wide array of regulations to safeguard against these dangers and to ensure a stable and profitable market.

There are two main areas in which major leagues have intervened: regulations in the sporting labor-market, e.g., reserve clause, transfer system, salary caps (Hunt and Lewis 1976; Kahn 2000; Feess and Muehlheusser 2003) and regulations regarding the distribution of revenues between clubs, e.g., gate and national TV-sharing (Szymanski and Késenne 2004, Dietl and Lang 2008, Peeters 2012). The main idea of revenue sharing is to transfer resources from rich clubs with a high local potential to poor clubs with a low local potential in order to offset inequalities between clubs (Quirk and Fort 1992, Szymanski 2003). The 
current revenue-sharing schemes differ widely among the major leagues. For example, the NHL operates a pool-sharing arrangement where locally-generated revenues (gate, concession, television, etc.) from the top 10 highest-grossing teams based on pre-season and regular season revenue is put into a central pool, which is then redistributed to financially struggling teams. The most important intervention in the labor market adopted in the major leagues are salary caps (Vrooman 1995, 2000) which limit the amount a club can spend on player salaries, either as a per-player limit or a total limit for the team's roster. Salary caps are in effect in all North American major leagues. For example, an NHL club must not spend more than US\$81.5 million on player salaries in the season 2019/20.

Compared with the North American model, the governance requirements of the SIHF are relatively loose, especially with respect to financial matters. In fact, the clubs' only obligation is to present their budgets to the SIHF, without the SIHF having any power to act or even to express an opinion. In contrast to the NHL, Swiss clubs are not subject to a salary cap. Except for the rule limiting the number of foreign players, there are few rules governing the market for Swiss players. This limit on the number of foreign players helps protect upcoming generations and the national team, and creates favorable conditions for Swiss players by putting them in a position of strength in the market. In this respect, the fact that Swiss ice hockey does not have a players' union might show that conditions for Swiss players are good enough for them not to need a union to protect their interests.

\section{Theoretical framework}

We extend Durand, Ravenel and Bayle (2005) as follows: In addition to the strategy of local potential (which is by definition dependent on the market environment and the arena), we examine the operation of three types of expertise. Our model is presented in Figure 1.

Marketing expertise has the goal of transforming the available local potential into revenues. The available money is then used for production. Managerial expertise is dedicated to keeping expenditures within the estimated and strategic limits, which will determine the financial results. Last, sporting expertise is crucial to ensure the productivity of the committed expenditures. It should be noted that the sports results influence club revenues, with success in the field facilitating ticket sales.

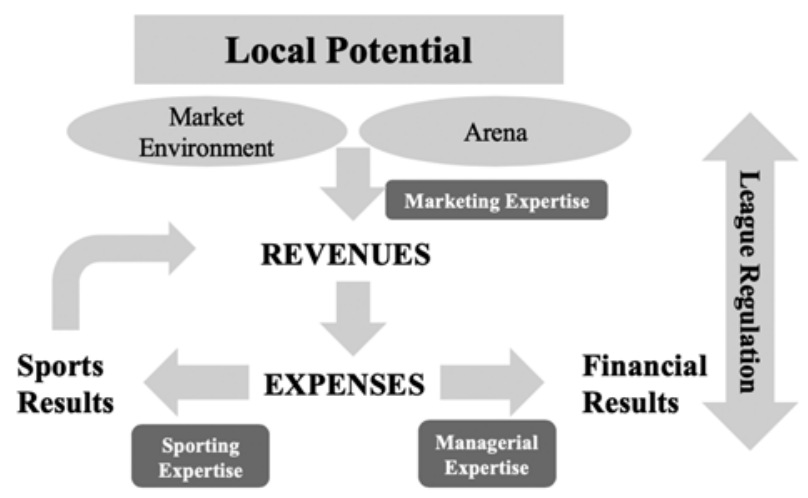

Figure 1. Model setup. 
The vital role of this triple expertise suggests that the correlation between local potential and sports and/or financial results is not absolute and that human know-how can compensate for environmental factors to some extent. A club with a powerful sales network, rigorous management and expert technical staff can compensate for a poor location. However, in the case of similar levels of expertise, location in a large city offers opportunities for better results.

One other key aspect is the role played by the league as the regulator for cross-subsidization policies. Since the economic regulation of the SIHF is weak, there is a significant correlation between a club's budget and its sporting results. This applies to both of Switzerland's top divisions, the SNL and the Swiss League. ${ }^{6}$ In addition, the two divisions differ in terms of the number of foreign players allowed (4 in the SNL, 2 in the Swiss League) and the teams' average budget, which is four times higher in the SNL ( $€ 20$ million) than in the Swiss League ( $€ 5$ million). ${ }^{7}$ Officially, the leagues are open, with a promotion/relegation system, but in practice the winner of the Swiss League is not always promoted to the SNL (only 8 times since 2000/01).

\section{Methods and data}

In this section, we first explain the underlying data and then we explain how we measured the key concepts of our model. We distinguish between an exogeneous factor, the local potential (which depends on the market environment and the arena), and endogenous factors such as marketing expertise, managerial expertise and sporting expertise.

\section{Data}

While the collection of data was mainly done for the 2018/19 season, some data covered the last five seasons (few data are coming from the league and most have been found through clubs and indirect sources such as Swiss newspaper articles). We also interviewed key experts (3 CEOs of professional clubs - Bern, Lausanne, Fribourg) and 4 specific master theses have been conducted on the professionalization of 4 ice hockey clubs between 2016 and 2019 (Ambri, Bern, Lausanne, Fribourg).

By considering that clubs are groups (limited company for the professional team, nonprofit/for-profit organization for the training center of a professional club, limited company for bar-restaurants, limited company for multifunctional arena business development), the measurement we have done is for the group and not only for the professional club.

We have done an empirical treatment of data to propose a typology of the 12 SNL clubs. We submitted our data and our results to the CEOs of the SNL clubs, which enabled us to revise some data and interpretations.

\section{Exogeneous variables}

\section{Market environment}

In the light of the literature, we measured the market environment via four indicators. First, we ranked the club's home agglomeration by size, from the largest, Zurich (pop. 1.3 million), to the smallest, Ambri (pop. 500). 
In addition to Zurich, which is a major world financial and academic center, three clubs are based in large (for Switzerland) cities: Geneva (pop. 585,000), Bern and Lausanne (pop. 415,000); three are in medium-sized cities: Lugano (pop. 150,000), Bienne and Zug (pop. 120,000); two are in small-to-medium-sized cities Fribourg (pop. 85,000) and Rapperswil (pop. 45,000); two are in small towns: Davos (pop. 12,000) and Langnau (pop. 10,000) and, unusually, one is in a small village Ambri (pop. 500).

Second, we measured a city's economic situation via per capita GDP. Per capita GDP is highest in Zug (100\% higher than average), Geneva and Zurich (both $40 \%$ higher than average), and lowest in Ambri and Langnau. This indicator provides a measure of the local population's wealth and their ability to consume their club's products. It is linked to the presence of companies providing employment and which may also invest in the local club (as shareholders, sponsors, etc.).

The third indicator was taxation. In fact, tax rates in Switzerland are not set by the national government but by the country's 26 cantons (regional political divisions), which have very different tax policies. Cantons with a socialist majority have high individual tax rates; therefore, players, whose earnings are quite high (€220,000 on average and up to $€ 700,000$ for the highest paid) are in the highest income tax bands. This variable is less discriminatory for commercial enterprises (and therefore the professional clubs) because the cantons tax company revenues/profits at similar rates. Differences in tax rates can lead to large differences in net earnings between players. Zug, and to a lesser extent Zurich (tax rate is $50 \%$ higher than Zug but 30\% lower than Geneva and Lausanne) are the cantons with the lowest personal income tax rates, whereas Geneva and Vaud have the highest rates $(32 \%$ and $35 \%$, respectively, that is, three times higher than in Zug, Switzerland's internal tax haven). With the exception of Zug, this variable is, nevertheless, quite neutral in so far as all the other SNL clubs are in cantons where tax rates are around or slightly above the average for Switzerland.

The final factor is local competition, as other leisure activities and other sports events can capture clients and, most importantly, sponsors, who will therefore give less, or nothing, to their local hockey club. Soccer is clearly the main competitor in cities where there is a successful and economically efficient professional soccer club (e.g., Bern, Zurich and, to a lesser extent, Geneva, Lugano and Lausanne). Nevertheless, many hockey clubs in small or medium-sized cities have a monopoly within their local area (e.g., Ambri, Davos, Langnau, Zug).

Given these factors, we combined the opinions of five experts ( 2 researchers who specialize in the economics of professional sport and 3 club directors) to determine the relative importance of each of the four indicators of local potential. The resulting weightings were: $40 \%$ for population size, $30 \%$ for economic wealth, $15 \%$ for tax rates and $15 \%$ for local competition.

We coded the different factors that influence the market environment as shown in Table 1 .

Using the weighted average of population size, economic wealth, tax rates and local competition, we calculate the market environment indices for each club as displayed in Figure 2 (grey bars).

Our results revealed a large degree of heterogeneity between clubs. The clubs with the best market environment were clearly Zurich (4.1) and Zug (4.2). However, the market environment of the clubs in Switzerland's other major cities, as indicated by our criteria, 
Table 1. Exogeneous variables.

\begin{tabular}{lcccccc}
\hline & \multicolumn{3}{c}{ Market Environment } & \multicolumn{2}{c}{ Arena } \\
\cline { 2 - 7 } CLUB & $\begin{array}{c}\text { Population } \\
\text { Size }\end{array}$ & $\begin{array}{c}\text { Economic } \\
\text { Wealth }\end{array}$ & $\begin{array}{c}\text { Tax } \\
\text { Rates }\end{array}$ & $\begin{array}{c}\text { Local } \\
\text { Competition }\end{array}$ & $\begin{array}{c}\text { Total } \\
\text { Capacity }\end{array}$ & $\begin{array}{c}\text { Exploitation } \\
\text { of capacity }\end{array}$ \\
\hline Bern & 4 & 4 & 2 & 2 & 5 & 4 \\
Zurich & 5 & 5 & 3 & 1 & 4 & 5 \\
Lugano & 3 & 4 & 3 & 2 & 3 & 3 \\
Zug & 3 & 5 & 5 & 5 & 3 & 4 \\
Lausanne & 4 & 4 & 1 & 2 & 4 & 5 \\
Davos & 1 & 3 & 3 & 5 & 2 & 3 \\
Bienne & 3 & 3 & 2 & 4 & 2 & 4 \\
Genève & 4 & 4 & 1 & 2 & 3 & 3 \\
Fribourg & 2 & 3 & 3 & 4 & 2 & 2 \\
Rapperswil & 2 & 3 & 2 & 5 & 2 & 3 \\
Ambri & 1 & 2 & 3 & 5 & 2 & 2 \\
Langnau & 1 & 2 & 2 & 5 & 2 & 3.3 \\
Average & 2.8 & 3.3 & 2.5 & 3.5 & 2.8 & \\
\hline
\end{tabular}

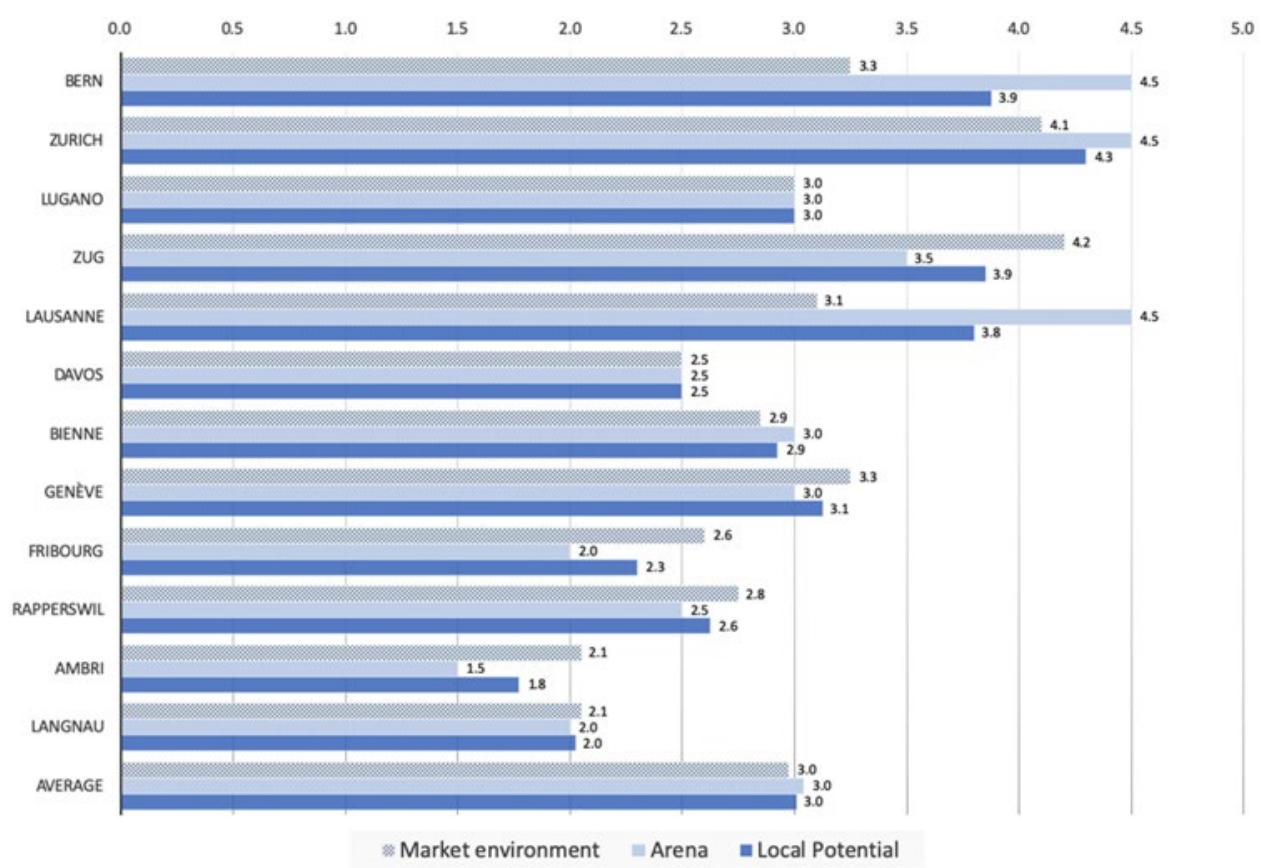

Figure 2. Market environment, arena and local potential.

tended to be relatively moderate: Geneva: (3.3), Bern (3.3) and Lausanne (3.1). Most of the clubs in smaller towns and cities had a worse market environment than the other clubs: Davos (2.5), Fribourg (2.6) and Rapperswil (2.8).

\section{Arena}

To calculate the arena index, we used two indicators: (i) arena capacity and (ii) potential for exploiting the arena's capacity, considering several criteria (seated/standing capacity; multifunctional dimension of facilities that allow games to be exploited to the full and the 
club to generate other revenues outside games; arena ownership, as ownership by the local authority can be considered a non-negligible form of indirect subsidy). Not owning the arena is not necessarily a problem for a club if the rent and maintenance fees they pay are low and below the real cost (another form of indirect subsidy).

Bern has a much larger arena than the other clubs (17,000 capacity vs. a league average capacity of 8,100$)$, but much of its capacity is standing (10,000). Of the 12 SNL clubs, only Zug, Bienne, Zurich, Bern and Lausanne have multifunctional arenas that give them the potential to generate additional revenues outside hockey games.

We coded arena capacity and the ability to exploit the arena as shown in summary Table 1 above, yielding the arena factor as displayed for the bright blue bars in Figure 2 above. Our results reveal that Bern, Zurich and Lausanne (since 2019) have a major competitive advantage with a score of 4.5. Some clubs have aging arenas that have not yet been renovated and lower-than-average capacities, around half of which is standing (Fribourg - renovation underway for 2020, Rapperswil and Langnau, which scored 2.5 and 2.0, respectively, and Ambri, whose obsolete ice rink was scored 1.5). These conditions do not allow optimal marketing. The other clubs are in an intermediate situation (Bienne, Lugano and Geneva obtain a score of 3.0 - thanks to support from their municipal councils).

\section{Local potential}

We obtained local potential scores by calculating the mean of market environment and arena. The local potential is displayed for the dark blue bars in Figure 2 above. Our results indicate that Zurich (4.3), Zug (3.9), Bern (3.9) and Lausanne (3.8) have greater local potential than the other clubs. Fribourg (2.3), Langnau (2.0) and Ambri (1.8) obtained the lowest scores on this exogenous variable.

\section{Endogenous variables}

In this section, we describe the endogenous variables (marketing expertise, managerial expertise, sporting expertise) in our model.

\section{Marketing expertise}

We used two measures to assess the marketing expertise needed to turn local potential into commercial results: arena occupancy rate and capacity for diversifying revenues (via the arena but also via other means involving different types of "clientele": arena naming, café and catering outside or inside the arena and operating during matches or throughout the year, merchandising, contributions from patrons or other revenues - cash injections from stakeholders and/or shareholders: organizing special events). We coded the two input factors for marketing expertise as shown in Table 2 (compare the first two columns titled 'Marketing').

With respect to the first point, there are clearly three types of club: those which succeed in exploiting arena occupancy: Lausanne (97\%), Zug and Langnau (96\%), Bern (95\%), Bienne (93\%), Fribourg (91\%); those which achieve moderate occupancy rates: Zurich and Lugano (86\%), Ambri and Geneva (84\%); and those which difficulty filling their arenas: Rapperswil (65\%) and Davos (63\%). 
Table 2. Endogenous variables.

\begin{tabular}{|c|c|c|c|c|c|c|c|}
\hline \multirow[b]{2}{*}{ CLUB } & \multicolumn{2}{|c|}{ Marketing } & \multicolumn{3}{|c|}{ Finance } & \multicolumn{2}{|r|}{ Sport } \\
\hline & Arena & Diversification & Budget & $\begin{array}{c}\text { Budget } \\
\text { Evolution }\end{array}$ & Dependence & Ranking & Budget/ranking \\
\hline Bern & 5 & 5 & 5 & 3 & 5 & 5 & 4 \\
\hline Zurich & 3 & 3 & 4 & 5 & 2 & 5 & 5 \\
\hline Lugano & 3 & 2 & 3 & 2 & 2 & 4 & 5 \\
\hline Zug & 4 & 3 & 4 & 5 & 3 & 4 & 4 \\
\hline Lausanne & 4 & 4 & 4 & 5 & 4 & 2 & 2 \\
\hline Davos & 2 & 3 & 4 & 3 & 3 & 3 & 3 \\
\hline Bienne & 4 & 4 & 3 & 5 & 4 & 1 & 2 \\
\hline Genève & 3 & 3 & 2 & 1 & 3 & 2 & 4 \\
\hline Fribourg & 3 & 4 & 3 & 1 & 5 & 2 & 3 \\
\hline Rapperswil & 1 & 2 & 2 & 2 & 4 & 1 & 2 \\
\hline Ambri & 2 & 3 & 2 & 1 & 3 & 1 & 2 \\
\hline Langnau & 3 & 3 & 1 & 2 & 4 & 1 & 4 \\
\hline Average & 3.1 & 3.3 & 3.1 & 2.9 & 3.5 & 2.6 & 3.3 \\
\hline
\end{tabular}

In terms of capacity to diversify revenues beyond the traditional trilogy of spectators-sponsors-public relations, Bern (5/5) is clearly an exception, as it has the capacity to diversify its revenues in every domain, especially catering inside the arena and, most importantly, outside the arena, where it set up a company in 2002 to manage 17 restaurants with an annual turnover of $€ 30$ million. In addition to this revenue, they also receive income from arena naming and from patrons. Bern is followed by Lausanne and Bienne, which carry out public relations actions and catering for sponsors, Fribourg (café and restaurant open year-round) and Davos (via the Spengler Cup), most of which scored 4/5 but through different levers. All of these clubs receive income from arena naming although it is difficult to know what percentage of the sums involved go to the clubs because their arenas are owned by the local authorities. Lugano and Rapperswil have had greater difficulty diversifying their revenues than the other clubs (2/5). Zurich appears to be an exception as, despite having the best local potential of all the league's clubs (4.3), it scored 3.0 for marketing expertise (compare the dark blue columns in Figure 3).

\section{Managerial expertise}

The indicators we used to measure the managerial expertise needed to turn these factors into financial results were: (i) a club's budget for the 2018/19 season, (ii) the increase in this budget over the last five years and (iii) financial dependence on one major source of revenue. Clubs that are highly dependent on a main sponsor, one or more shareholders, or a bank covering its deficit and/or debts are in less favorable positions. This is the case for Zurich, for example. We coded the budget, budget evolution and financial dependence as shown in the summary Table 2 above (compare the 3 columns titles 'Finance'). By taking the average of the three factors, we obtain the clubs' managerial expertise displayed for the bright blue columns in Figure 3 below.

Our results indicate that Bern and Lausanne (4.3) and, to a lesser extent, Bienne and Zug (4.0) stand out, even though Bern has a much larger budget (2.5 times the average budget and twice as much as the second highest budget) whose profitability is difficult to measure. Geneva and Ambri (each 2.0) are in the poorest position, closely followed by Lugano and Langnau (2.3). However, because most of the clubs do not publish their accounts, it is 


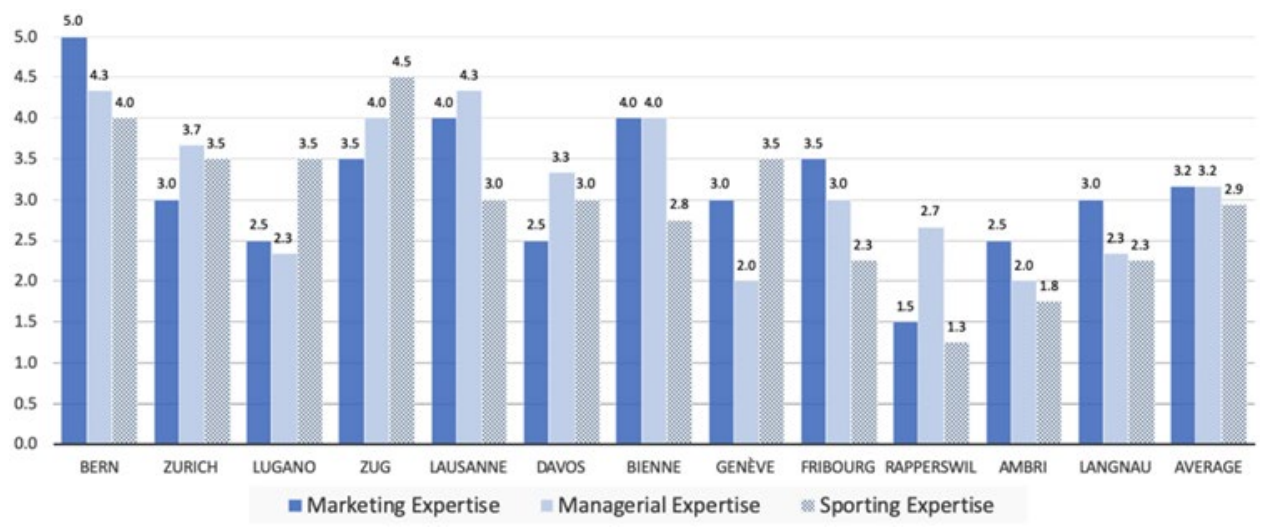

Figure 3. Marketing, managerial and sporting expertise.

difficult to analyze their financial results and their level of debt due to the need to work from secondary data.

\section{Sporting expertise}

Rather than assessing sporting expertise directly, we measured sporting results via a club's average league position over the last five seasons. We weighted these sporting results against the club's average budget for the last five seasons in order to obtain a measure of efficiency in terms of sporting results.

We did not consider results for the junior team or the training center, as our experts felt that this variable is not relevant for Switzerland because the clubs' results in these areas are comparable and, contrary to soccer, there is no economic model linked to the sale of young players.

We coded the two input factors for the sporting expertise as shown in Table 2 (compare the last two columns titled 'Sport') above yielding an overall sporting expertise as shown for the grey columns in Figure 3 above. We found substantial differences in terms of sporting expertise: Zug (4.5) stands out ahead of Bern (4.0), followed by Zurich, Genève and Lugano (3.5). Regarding its expertise, Fribourg (2.3) had more difficulties, as well as the smallest clubs Ambri (1.8) and Rapperswil (1.3) that had lower expertise.

\section{Summary}

This section summarizes our data. Figure 4 shows scatter diagrams to visualize the combination of local potential and expertise. Clubs above the bisecting line achieve higher expertise than their local potential whereas clubs below the line fall short of their local potential. Similarly, Figure 5 visualizes the clubs' capability to use their local potential by depicting the clubs' expertise relative to their local potential.

Overall, only a few clubs manage to make optimal use of their local potential in all three areas of expertise. This is the case for Bern, Davos and Langnau, whereas Zurich, Geneva and Rapperswil have the greatest difficulty in this area. 

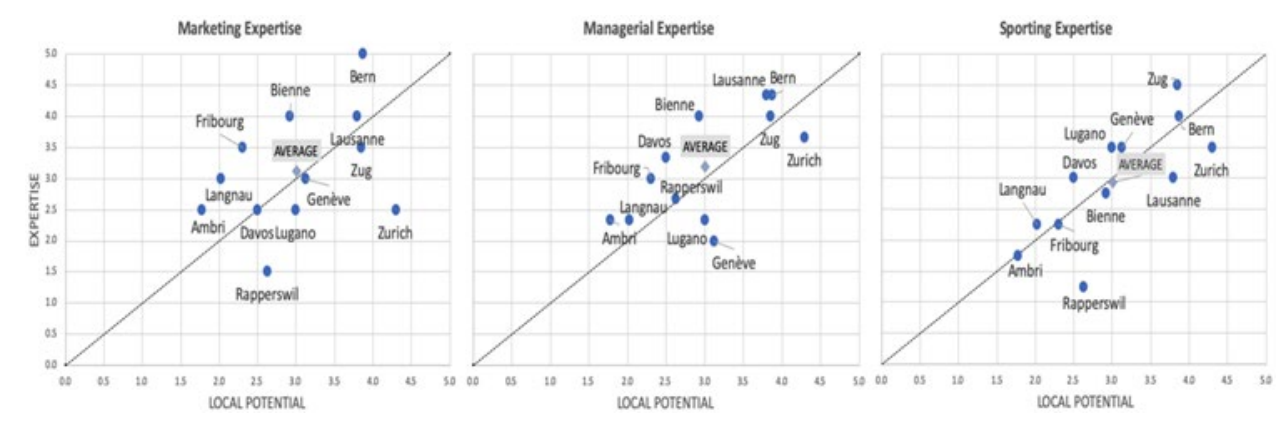

Figure 4. Expertise and local potential.

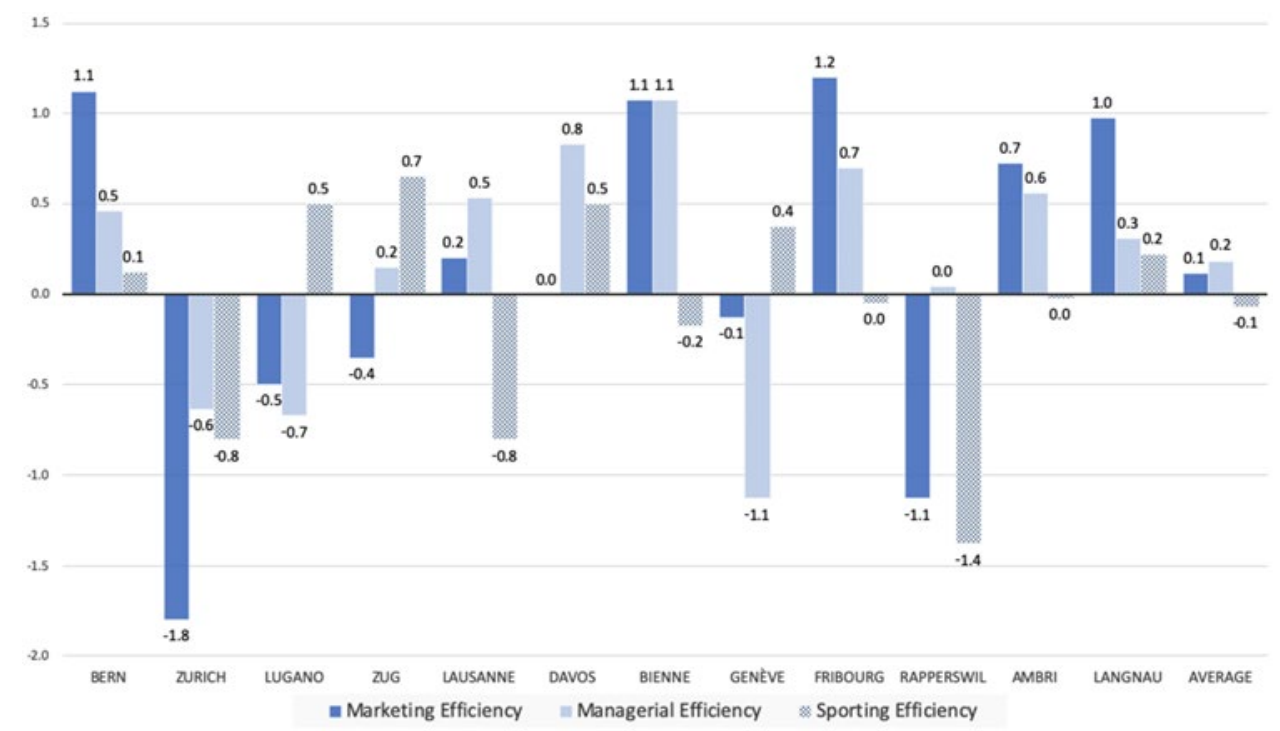

Figure 5. Expertise relative to local potential.

\section{Results}

Our data enabled us to draw up an empirical typology of four types of club as displayed in Figure 6: regional flagships, sporting high achievers with unexploited local potential, modest clubs overshadowed by a larger rival and atypically successful clubs.

\section{Regional flagships: Bienne, Fribourg and Lausanne}

These three clubs achieve very high arena occupancy rates that are well above the league average of $86 \%$ (Lausanne: 97\%, Bienne: 93\%, Fribourg: 91\%). Since ticketing is strong, as well as VIP sponsoring and catering given their catchment areas, they are much better than the other clubs at exploiting this potential (averages of 3.2 for marketing expertise and managerial expertise): 4.0 for marketing expertise and 4.3 for managerial expertise for Lausanne (for a local potential of 3.8), and 4.0 and 4.0 for Bienne (despite a local potential of only 2.9). This is also the case for Fribourg, even though it has much lower 

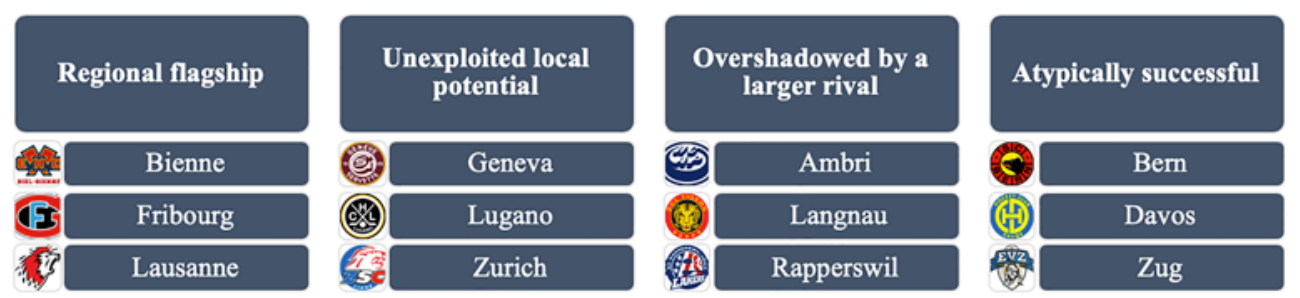

Figure 6. Typology of SNL clubs.

local potential (2.3, due to the city being 5 times smaller and poorer than the other two cities). Nevertheless, it has exploited this potential (3.5 for marketing expertise) by generating substantial support from local people and businesses in the city, the conurbation and even beyond the canton. It is no surprise in this type of situation that the cantonal bank is the majority shareholder alongside other companies in the region and that the club is massively sponsored by all the canton's 350 partners. Popular support is also manifest in the use of the arena's café/restaurant, which is open throughout the year and provides more than $20 \%$ of the club's budget. Although the arena occupancy rate is high, the venue is not multifunctional, a situation that might soon change with the building of a new, 8,500-capacity arena for the $2020 / 21$ season.

All three clubs have received public authority support through finance for building their arenas. These arenas are at the heart of a new economic model supported by a leading local business (Lausanne: Vaudoise Assurance Arena since 2019. Bienne: Tissot Arena since 2015. Tissot is part of the Swatch Group, which is based in Bienne. Fribourg: BCF-Arena since 2010).

However, these clubs differ in two ways: (i) They have very different shareholder profiles: Lausanne is owned by an American sports event promoter, which is unusual in Switzerland where most clubs are owned by local shareholders/patrons. Bienne has numerous small shareholders, as does Fribourg, alongside its main shareholder, the cantonal bank. (ii) Local competition is strong in Lausanne, but the sporting and marketing decline of the city's soccer club in the 2010s and the construction of a new arena has enabled the ice hockey club to become a regional flagship. This competition is weaker in both Bienne and Fribourg, whose hockey clubs therefore have a monopoly over this position of flagship for the city.

\section{Unexploited local potential: Geneva, Lugano and Zurich}

Zurich, Geneva and Lugano are sporting high achievers with large local potentials but their local potential is unexploited in terms of both marketing expertise and managerial expertise (4.3 vs. 3.0 and 3.7, respectively, for Zurich due to the state of its ice rink, although the club plans to build a new arena for 2022; 3.0 vs. 2.5 and 2.3 for Lugano, and 3.1 vs. 3.0 and 2.0 for Geneva. However, all three clubs have higher sporting expertise than the other clubs (3.5 when the average is 2.9). In all three cases, the clubs have a patron as owner/shareholder. Lugano is owned by a local patron, the Mantegazza family, which runs the canton's leading real estate agency, in conjunction with numerous small shareholders. Shares in the Zurich club are held by two powerful businessmen: W. Frey, Zurich's president and main shareholder, and P. Spuhler. Geneva has a single shareholder in the form of Genève Sport, an offshoot 
of the 1890 Foundation which oversees activities relating to soccer, ice hockey and rugby. The 1890 Foundation is itself part of the Hans Wilsdorf Foundation, which owns the watchmakers Rolex, whose world headquarter is in Geneva. All three clubs face strong local sporting competition and this may explain their difficulties in exploiting their local potential.

\section{Overshadowed by a larger rival: Ambri, Langnau and Rapperswil}

Clubs in this category have low (2.6 for Rapperswil and 2.0 for Langnau, compared with an average of 3.0) or very low (1.8 for Ambri) local potential and an arena that is difficult to operate due to age and/or dilapidated state (Ambri). However, two of the three clubs boast massive levels of support from locals (arena occupancy rates are very high for Langnau with 96\% and good for Ambri with 84\%; due to bad sporting results Rapperswil with $65 \%$ has more difficulties) and local businesses due to their high marketing expertise (3.0 for Langnau and 2.5 for Ambri).

Ambri is owned by a donor's club that was formed in 2002 by 200 local businesses. This is also the case for Rapperswil, which has more than 1,500 shareholders. Langnau's shares are owned by three local entrepreneurs in the Emmental region.

These three clubs are overshadowed by a larger club, leading to a 'David versus Goliath' rivalry in derby games. Ambri's rival is Lugano (the rich tourist capital of the Tessin canton vs. a small Tessin village); Rapperswil's rivals are Zug's and Zurich's hockey clubs and St. Gallen's soccer club; Langnau's rival is Bern (Switzerland's capital vs. a rural Emmental village center $30 \mathrm{~km}$ from Bern) and to a lesser extent Bienne. In terms of optimizing their sporting expertise, Langnau (2.3) has been more successful than Ambri (1.8) and Rapperswil (1.3), which are the clubs that struggle the most in the league.

\section{Atypically successful club: Bern, Davos and Zug}

These three clubs are atypical because they obtain at least $25 \%$ of their revenues from resources that the league's other nine clubs do not have.

\section{Bern: a shrewd restaurant owner}

Bern exploits its local potential (3.9) on all three types of expertise (5.0 for marketing, 4.3 for management and 4.0 for sport). Hence, it exploits each category: its private, multifunctional arena, which has a high occupancy rate of 95\% despite having an unusually large arena for Switzerland and Europe with a total capacity of 17,000 (with 10,000 standing places) for which it has had a lucrative naming contract since 2007. In 2002, the club created its own catering company, SportGastro AG, whose 17 restaurants across the city contribute $€ 30$ million (55\%) to the club's budget. The particularity of this model is that $50 \%$ of receipts come from this diversification whose profitability is, nevertheless, difficult to assess, even if the SC Bern Group announced a small, positive annual result of $€ 4,300$ in 2019 and has a low level of debt. The club's shares are in the hands of a small and stable group of investors, including the multi-millionaire main shareholder H. Dietrich. For the last 20 years, this small group of shareholders has handed their power to a strong general manager (Marc Lüthi), who is also a shareholder and one of the club's five board members. 
This club has supra-regional brand equity. In 2014/15, it joined forces with five other clubs from five other European countries to set up a new champions league. It is one of only a few clubs to have its eye on Europe and the potential for international expansion.

\section{Davos: the resilient Mountain town}

Davos is atypical in two ways. It is the only survivor from the mountain-resort clubs that dominated Swiss ice hockey in the 1960s. The town's small population $(12,000)$ also explains why the arena has a low occupancy rate, even though it has a slightly lower than average capacity $(6,800$ places, 3,400 of which are seated). These factors mean the club has only a moderate local potential (2.5). However, a very lucrative international competition, the Spengler Cup, which the club has hosted between Christmas and New Year every year since 1923, provides more than $20 \%$ of its budget. There is also a donor's club with 60 members each provide approx. $€ 21,500$ every year. In addition, the arena (Valiant Arena) has a naming contract with one of Switzerland's largest corporate banks.

\section{Zug: exploiting an exceptional local potential}

Zug has a unique market environment due to the wealth of its local population (twice as high as in the other 11 clubs), low tax rates (twice as low as the average for all the clubs), and the lack of local competition. This explains why Zug, despite having a population of 120,000 , has a slightly better market environment than the much larger city of Zurich (4.2 vs. 4.1). Since 2010, the club has had a new, 7,200-capacity multifunctional arena with a very high occupancy rate $(97 \%)$ that provides further income through a naming contract with a large local company, Bossard. These characteristics give Zug an exceptional local potential compared with the other clubs ( $2^{\text {nd }}$ behind Zurich with 3.9), which the club exploits well in terms of marketing, managerial and sporting expertise. In addition, a passionate patron-shareholder who made his fortune in the pharmaceuticals industry, joined the club as president in 2015 . He has invested $€ 86$ million in order to build a unique, high-performance center that is due to open in 2020 .

\section{Conclusion}

The concept of local potential is central to understand the evolution of the clubs' economic models and the need of regulation by the league. In this respect, the main contribution of our study is both methodological and empirical by showing whether the SNL clubs were able to exploit their local potential.

\section{Local potential and evolution of the clubs' economic models}

Given that the internationalization potential is relatively weak, since the end of the 2000s, all clubs have been trying to exploit their local potential in order to stay competitive, notably around their arenas, sometimes incorporating urban development and the valorization of their catchment areas. Some clubs had been left behind but are starting to catch up: Lausanne since September 2019 via a multifunctional arena with a capacity of 9,600 for hockey games and 12,000 for other events; Fribourg with a privately financed, 8,500-capacity arena planned 
for the 2020/21 season; Zurich with an 11,600-capacity arena due for June 2022 (a project supported by a $€ 100$ million loan from the city and by the canton, the national government and patrons); Ambri with a privately financed, $€ 43$ million, 7,000-capacity arena due for September 2021; Geneva is in discussion to build a new arena in 2022.

Although Swiss ice hockey can be proud that, over the years, it has become a major player in international ice hockey, the potential for developing its national championship appears limited and dependent on the growth of hockey across Europe. However, for European hockey to expand it will have to create and ensure the long-term future of a European competition capable of generating enough resources to attract the continent's top clubs, as soccer has done via the UEFA Champions League and, to a lesser extent, the Europa League. Such a competition already exists, but it is still in its infancy. In fact, the first European competition was held during the $2008 / 09$ season, when it was won by the Swiss club Zurich Lions. This initial attempt was soon abandoned as the competition format failed to generate enough enthusiasm from either clubs or fans. It was not until the 2014/15 season that a new European competition was created - the Champions Hockey League (CHL). Although the competition has increased in popularity over the years, the clubs are still not convinced of its value. Another possible internationalization scenario would be to adopt the NHL's multi-country approach, thereby creating a European league that would include Switzerland's top clubs. However, this would put an end to the current league format. It would also require clubs to abandon the European model and spell the end of the federation's control. This approach would require a show of strength from the top clubs in order to succeed, a scenario that appears highly unlikely in the short-to-medium-term given the current political, economic and cultural balance.

The current model makes it difficult to market television rights in a European hockey market that is struggling to find its feet. In Switzerland, most television rights are national and are paltry compared with television rights for soccer in Europe. As well as being a small market of 8.5 million consumers, Switzerland has four languages, which makes it difficult to obtain large sums for television rights, including internationally, where the NHL has captured almost the entire market. During the 2006/07 season, the SIHF sold part of the broadcasting rights for National and Swiss League games to private channels. The last signed contract rose to $€ 30$ million per season (2018-2022) provided windfalls of approximately $€ 1.6$ million per season for each SNL club and approx. $€ 300,000$ per season for each Swiss League club. Although this deal represents a substantial injection of cash for each SNL club, on average it covers only $10 \%$ of a club's budget.

Switzerland's hockey clubs are in a niche market that most clubs exploit well or are starting to exploit well. However, it remains Swiss-centric and has to be highly regulated by the league to ensure it is profitable for shareholders and to finance the major investments made in arenas, whose financial arrangements are less dependent on financing and public property.

\section{Towards an economic regulation by the Swiss ice hockey federation?}

Our data indicate that the clubs' revenues have considerably increased over the recent years but at the same time the clubs face ever increasing player salaries and the need to invest into infrastructure (e.g. arena). This has led to a situation of low rentability and an accumulation of debt so that the question arises whether the league should limit the 
player salaries. In contrast to its North American counterpart, the SNL has not yet introduced a salary cap mechanism so far. Among the reasons for the past failure to introduce a salary cap are the organizational differences between the SNL and the NHL. In the NHL, salary caps are now an integral part of the system of labor relations. The maximum and minimum that should be devoted to player salaries is negotiated between the players' unions and the team owners and is fixed in the Collective Bargaining Agreements (CBAs) ${ }^{8}$

Obviously, the labor relations approach employed by the hermetic NHL is not feasible within the association-governed hockey pyramid in Switzerland. Associations cannot be compared with the team owners in an American major league, which represent the demand side of the respective labor market. Instead, associations are conceived of as democratic governing bodies that aim to integrate all important stakeholders of hockey in a certain geographic region, including the players and, of course, the representatives of amateur hockey. Due to this additional stakeholder diversity, it follows that decision-making processes concerning the introduction of salary caps would be much more complicated in the Swiss, association-governed hockey pyramid because the interests of various stakeholders need to be properly balanced. In addition, the significant market heterogeneity within the SNL has to be considered. The North American system of an absolute capped salary amount for all clubs covered by the CBA would probably be difficult to implement in the highly heterogeneous SNL. As a consequence, the only workable solution in the Swiss context seems to be a percentage-of-revenue cap (cf., Dietl et al. 2012).

\section{Limits and perspectives}

Our study has a number of limits, most notably due to the difficulty in obtaining financial data given that most clubs do not publish their accounts and the SIHF does not publish data on the economics and financial control of clubs, in contrast to soccer and the North American leagues. In addition, it is sometimes difficult to obtain complete data for groups of which the professional clubs are part. The existence of several companies makes it difficult to compare similar data between clubs. Similarly, it is difficult to identify all the financial arrangements relating to the construction and renovation of arenas and dealings that may be associated with them (development of real estate businesses, event organization, etc.).

A possible avenue for future research would be to integrate the issue of the clubs' social or societal expertise in order to obtain a better understanding of their (social, economic, environmental) impacts on the local community. This aspect also has to be considered when examining the clubs' strategies, which are increasingly incorporating the issue of social responsibility.

\section{Notes}

1. Note that the Bosman ruling does not apply because Switzerland is not part of the European Union.

2. The National League (formerly National League A) is Swiss ice hockey's first division.

3. North America's National Hockey League (NHL) is the world's most prestigious ice hockey league with the highest standard of play. 
4. The Kontinental Hockey League (KHL), mostly based in Russia, is the world's second league in terms of standard of play.

5. It is important to mention that scholars in sports economics refers to clubs operating in regions with high (low) local economic potential as club with a large (small) market size, cf., Quirk and Fort (1992), Marburger (1997) and Szymanski (2003).

6. The Swiss League (formerly National League B) is Swiss ice hockey's second division.

7. We converted and rounded all currencies given in Swiss francs (CHF) into Euro (€) by using the average annual exchange rate of $1.16 € / C H F$ from 2018.

8. This kind of labor dispute entails strikes and lookouts, potentially resulting in the loss of part of or an entire season, as occurred several times in the NHL (cf., Staudohar 1997, 2005).

\section{Disclosure statement}

No potential conflict of interest was reported by the authors.

\section{References}

Andreff, W. 2000. "Lévolution du modèle Européen de financement du sport professionnel." Reflets et perspectives de la vie économique 39 (2/3): 179-196.

Andreff, W., and P. Staudohar. 2000. "The Evolving European Model of Professional Sports Finance." Journal of Sports Economics 1 (3): 257-276. doi:10.1177/152700250000100304.

Augustin, J. P. 1995. Sport, Géographie et aménagement. Paris: Nathan.

Bale, J. 1993. Sport, Space and the City. London: Routledge.

Busset, T. 2000. “...Quelques joies au milieu de la nature maussade de l'hiver: les relations villemontagne vues à travers l'essor du hockey sur glace en Suisse... Histoire des Alpes 5: 241-250.

Carlsson, B., and J. Backman. 2015. "The Blend of Normative Uncertainty and Commercial Immaturity in Swedish Ice Hockey." Sport in Society 18 (3): 290-312. doi:10.1080/17430437.2014. 951438.

Copeland, R., W. Frisby, and R. McCarville. 1996. "Understanding the Sport Sponsorship Process from a Corporate Perspective." Journal of Sport Management 10 (1):32-48. doi:10.1123/jsm.10.1.32.

Danielson, M. 2001. Home Team: Professional Sports and the American Metropolis. Princeton: Princeton University Press.

Dietl, H., and M. Lang. 2008. "The Effect of Gate Revenue-Sharing on Social Welfare." Contemporary Economic Policy 26 (3): 448-459. doi:10.1111/j.1465-7287.2007.00090.x.

Dietl, H., R. Fort, and M. Lang. 2011. "International Sports League Comparisons." In Routledge Handbook of Sport Management, edited by L. Robinson, P. Chelladurai, G. Bodet, and P. Downward, 388-404. New York, NY: Routledge.

Dietl, H., E. Franck, M. Lang, and A. Rathke. 2012. "Salary Cap Regulation in Professional Team Sports." Contemporary Economic Policy 30 (3): 307-319. doi:10.1111/j.1465-7287. 2011.00265.x.

Durand, C., and E. Bayle. 2002. "Public Assistance in Spectator Sport: A Comparison between Europe and the United States." European Journal of Sport Science 2 (2): 1-19. doi:10.1080/ 17461390200072206.

Durand, C., L. Ravenel, and E. Bayle. 2005. "The Strategic and Political Consequences of Using Demographic Criteria for the Organization of European Leagues." European Journal of Sport Science 5 (4): 167-180. doi:10.1080/17461390500344321.

Falconieri, S., F. Palomino, and J. Sákovics. 2004. "Collective versus Individual Sale of Television Rights in League Sports." Journal of the European Economic Association 2 (5): 833-862. doi:10.1162/1542476042782305.

Feess, E., and G. Muehlheusser. 2003. “Transfer Fee Regulations in European Football." European Economic Review 47 (4): 645-668. doi:10.1016/S0014-2921(02)00308-2. 
Fort, R., and J. Quirk. 1995. "Cross-Subsidization, Incentives, and Outcomes in Professional Team Sports Leagues.” Journal of Economic Literature 33: 1265-1299.

Hunt, J., and K. Lewis. 1976. "Dominance, Recontracting, and the Reserve Clause: Major League Baseball." American Economic Review 66 (5): 936-943.

Kahn, L. 2000. “The Sports Business as a Labor Market Laboratory." Journal of Economic Perspectives 14 (3): 75-94. doi:10.1257/jep.14.3.75.

Kidd, B. 2013. “Canada's 'National' Sport." Sport in Society 16 (4): 351-361. doi:10.1080/17430437. 2013.785747.

Lamprecht, M., A. Fischer, and H. Stamm. 2014. Sport Switzerland 2014: Activité et consommation sportives de la population Swiss. Macolin: Office fédéral du sport OFSPO.

Marburger, D. 1997. "Gate Revenue Sharing and Luxury Taxes in Professional Sports." Contemporary Economic Policy 15 (2): 114-123. doi:10.1111/j.1465-7287.1997.tb00471.x.

Moret, O., and F. Ohl. 2019. "Social Class, the Elite Hockey Player Career and Educational Paths." International Review for the Sociology of Sport 54 (8): 899-920. doi:10.1177/1012690218765759.

Moret, O., A. Traclet, A. Clémence, and F. Ohl. 2019. "The 'Aggressive Style': Genesis of an Ambiguous Resource for Swiss Hockey and Football Players." Sport in Society 22 (3): 399-415. doi:10.1080/17430437.2018.1490267.

Neale, W. 1964. "The Peculiar Economics of Professional Sports: A Contribution to the Theory of the Firm in Sporting Competition and in Market Competition." The Quarterly Journal of Economics 78 (1): 1-14. doi:10.2307/1880543.

Peeters, T. 2012. "Media Revenue Sharing as a Coordination Device in Sports Leagues." International Journal of Industrial Organization 30 (2): 153-163. doi:10.1016/j.ijindorg.2011.07.004.

Quirk, J., and R. Fort. 1992. Pay Dirt: The Business of Professional Team Sports. Princeton, NJ: Princeton University Press.

Robidoux, M., and P. Trudel. 2006. Hockey Canada and the Bodychecking Debate in Minor Hockey, Artificial Ice: Hockey, Culture, and Commerce. Peterborough: Garamond Imprint.

Rottenberg, S. 1956. “The Baseball Players' Labor Market." Journal of Political Economy 64 (3): 242-258. doi:10.1086/257790.

Szymanski, S. 2003. “The Economic Design of Sporting Contests." Journal of Economic Literature 41 (4): 1137-1187. doi:10.1257/jel.41.4.1137.

Szymanski, S., and S. Késenne. 2004. "Competitive Balance and Gate Revenue Sharing in Team Sports." Journal of Industrial Economics 52 (1): 165-177. doi:10.1111/j.0022-1821.2004.00220.x.

Staudohar, P. 1997. “The Baseball Strike of 1994-95." Monthly Labor Review 120: 21-27.

Staudohar, P. 2005. “The Hockey Lockout of 2004-05." Monthly Labor Review 128: 23-29. doi:10.21916/mlr.2013.24.

Vrooman, J. 1995. “A General Theory of Professional Sports Leagues.” Southern Economic Journal 61 (4): 971-990. doi:10.2307/1060735.

Vrooman, J. 2000. “The Economics of American Sports Leagues." Scottish Journal of Political Economy 47 (4): 364-398. doi:10.1111/1467-9485.00169.

Whitson, D., and R. Grunenau. 2006. Artificial Ice: Hockey, Culture, and Commerce. Peterborough: Broadview Press.

Yonnet, P. 1998. Systèmes des sports, Gallimard, Bibliothèque des sciences humaines.

Zimbalist, A. 2003. "Sport as Business." Oxford Review of Economic Policy 19 (4): 503-511. doi:10.1093/oxrep/19.4.503. 